\title{
Celio-mesenteric Trunk Associated with Giant Omphalocele: Surgical Consequences
}

\author{
Tronco Celíaco-Mesentérico Asociado con Onfalocele Gigante: Consecuencias Quirúrgicas
}

Laquievre Antoine ${ }^{1,2}$; Hitier Martin ${ }^{2,3}$; Petit Thierry ${ }^{1}$; Ravasse Philippe ${ }^{1,2} \&$ Rod Julien $^{1,2}$

LAQUIEVRE, A.; HITIER, M.; PETIT, T.; RAVASSE, P. \& ROD, J. Celio-mesenteric trunk associated with giant omphalocele: surgical consequences. Int. J. Morphol., 35(3):938-941, 2017.

SUMMARY: We report the first case of a newborn presenting with a celio-mesenteric trunk variation associated with a giant omphalocele. The celio-mesenteric trunk was unexpected and unseen during the staged surgical closure. After partial reintegration of the liver, the newborn presented refractory hypovolemia with anuria, leading to redo surgery. This procedure revealed ischemia of the liver and necrosis of the entire gastrointestinal tract except the colon. Despite treatment, including liver externalization, the infant did not survive. The autopsy revealed a celio-mesenteric trunk, a rare anomaly characterized by a common origin of the celiac axis and the superior mesenteric artery from the aorta. This association may explain the dramatic consequences of the staged closure procedure. Awareness of the association of celio-mesenteric trunk and omphalocele would allow the surgeon to take extra care during this delicate surgery.

valproate.

KEY WORDS: Celio-mesenteric trunk; Mesenteric arterial variation; Mesenteric ischemia; Giant omphalocele; Sodium

\section{INTRODUCTION}

The celio-mesenteric trunk (CMT) is a rare vascular anomaly, characterized by the celiac artery branches and the superior mesenteric artery arising from a single trunk on the anterior wall of the abdominal aorta. This anatomic variation can have major clinical implications. Complications such as aneurysm (Ailawadi et al., 2004), occlusive disease (Ailawadi et al.), compression by the median arcuate ligament (Lee et al., 2011) and stenosis with lethal consequences (Lovisetto et al., 2012) have only been described in adults. To our knowledge, no CMT has ever been described with a giant omphalocele. Here we describe the first case of CMT with giant omphalocele, discuss its cause and the lesson learned.

\section{CASE REPORT}

A female infant was born at 37 weeks' gestation, with a birth weight of $2.870 \mathrm{~kg}$. There had been antenatal monitoring since the prenatal ultrasound diagnosed an omphalocele, without any other obvious associated anomaly (the caryotype and fetal cardiac ultrasound were normal). The mother's medical history reported epilepsy, treated with valproic acid (Depakine ${ }^{\odot}$ ), obesity and active smoking. The birth examination revealed a giant omphalocele, with an externalized liver as well as partial digestive malrotation. A staged surgical closure method was performed by silastic silo with partial reintegration of the liver without the mesenteric bowel in order to avoid abdominal compartment syndrome. The post-operative period was characterized by hypovolemia refractory to effective vascular filling, as well as anuria, although respiratory function and perfusion of the lower limbs were preserved. Initially, a cardiac ultrasound revealed good venous return, excluding any abdominal compartment syndrome. Nevertheless, the clinical and laboratory findings (lactic acidosis) suggested mesenteric ischemia, and a redo procedure was performed 32 hours after the initial surgery. An ischemic liver and ischemia from the jejunum to the ileum were observed, and only the colon was safe. The liver was externalized to limit abdominal compression. Unfortunately, the patient died 12 hours later. 
The autopsy revealed a CMT from the ventral part of the abdominal aorta (Fig. 1). Two trunks arose separately from a very short CMT: 1) the gastro-splenic trunk divided into the left gastric artery and the splenic artery; and 2) the hepatomesenteric trunk divided into the common hepatic artery and the superior mesenteric artery.

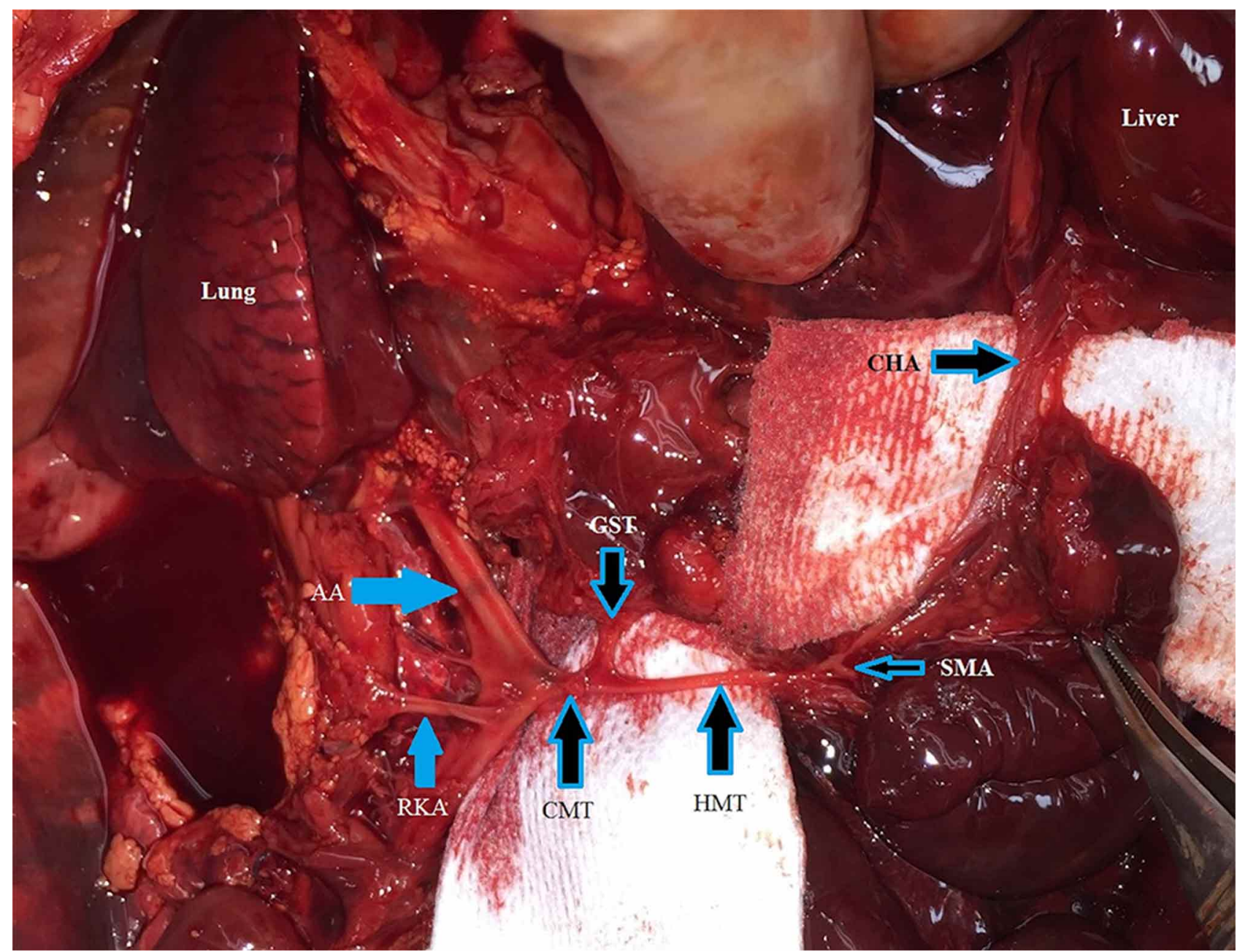

Fig. 1. View of the dissection from this case, showing the celio-mesenteric trunk (CMT) (black arrow), arising from the ventral aspect of the abdominal aorta (AA). Two trunks arise separately from the CMT: the gastro-splenic trunk (GST) and the hepato-mesenteric trunk (HMT) (black arrows). The gastro-splenic trunk divided into the splenic artery and the left gastric artery. The hepato-mesenteric trunk (HMT) divided into the common hepatic artery (CHA) and the superior mesenteric artery (SMA). Inferior to the CMT, the abdominal aorta branches into the right kidney artery (RKA).

\section{DISCUSSION}

It is estimated that anomalous origins of the celiac artery and the superior mesenteric artery occur in $7 \%$ of people (Michels, 1955; Michels et al., 1968). A common origin for these two arteries from the abdominal aorta is an extremely rare occurrence, reported in $0.25 \%$ of the population (Michels; Michels et al.). First Tandler (1904), then Morita (1935), discussed the embryological aspects of this anomaly. The splanchnic arteries arise at an early stage of fetal development (fourth week) as paired ventral segmental arteries from the paired dorsal aorta to supply the yolk sac. The fetal digestive tube is supplied by four primitive splanchnic roots which arise from the abdominal aorta. There is a ventral longitudinal anastomosis (Lang's anastomosis) between these branches. Normally, the first root forms the left gastric artery, the second root forms the splenic artery and the third root forms the common hepatic artery. The closure of the longitudinal anastomosis between the third and the fourth root, and the coalescence of roots 1 to 3 , form 
the celiac trunk and the superior mesenteric artery (Tandler). Anomalous ramification of the celiac trunk and the superior mesenteric artery is due to the disappearance of the primitive ventral splanchnic arteries and their longitudinal anastomosis (Morita) (Fig. 2).

Many classifications of anatomical variations in the celiac trunk have been described in the literature. The most commonly used was proposed by Michaels (1955) (Table I). The present case belongs to type 6 of the Michaels classification.

An omphalocele is often described as being giant when the abdominal wall defect size is $>5 \mathrm{~cm}$, or when there is more than 50 or $75 \%$ of the liver within the sac (Mitanchez et al., 2010). The mortality rate is very high, from $0 \%$ to 46 $\%$, due to infections, intestinal obstruction, or pulmonary or renal failure, and there is a high frequency of associated anomalies (Bauman et al., 2016). Attempting primary closure of a giant omphalocele often results in abdominal compartment syndrome (Bauman et al.). This syndrome is defined as increased intra-abdominal pressure and organ failures (renal failure, hemodynamic instability, bowel obstruction or ischemia, inferior vena cava obstruction) (Bauman et al.). In our case, the staged surgical closure was performed to reduce this complication. The evolution after the initial procedure was surprising because there was no abrupt increase in abdominal pressure during the procedure and the abdominal compartment syndrome was incomplete. As a result of the abnormal postoperative evolution, an autopsy was suggested and performed. The discovery of a CMT during the procedure suggested that the partial liver reduction had compressed the CMT or the hepato-mesenteric trunk. We deduced that the compression had a lethal effect on the patient, with full stoppage of splanchnic arterial supply, causing superior mesenteric ischemia, with an incomplete abdominal compartment syndrome.

Finally, in order to explain the association of two anatomic variations, three hypotheses need to be discussed: either one is the consequences of the other; or the 2 have a common cause; or the two are a coincidental association. The CMT is formed during weeks 4 to 9 of intrauterine life (Tandler). The omphalocele appears during this period, as the lateral and craniocaudal abdominal folds normally close in utero at 5 weeks of gestation (Bauman et al.). However, an omphalocele would be unlikely to be the cause or the consequences of CMT as these structures evolve independently during embryogenesis. The cause of the omphalocele in our case may be the valproic acid, as it has been associated with many cases of anterior abdominal wall defect, and two cases of giant omphalocele (Boussemart et al., 1995). Nevertheless, our case is the first to report an association of CMT and valproic acid, which is not enough to demonstrate a cause and effect relationship between omphalocele, CMT and valproic acid.

Whatever the cause, surgeons must be aware of CMT associated with omphalocele as surgical treatment of omphalocele will increase the risk of gastrointestinal tract ischemia, even in the absence of abdominal compartment syndrome.

Consequently, we recommend extra care when performing this procedure, and identifying vascular variations using an ultrasound Doppler.

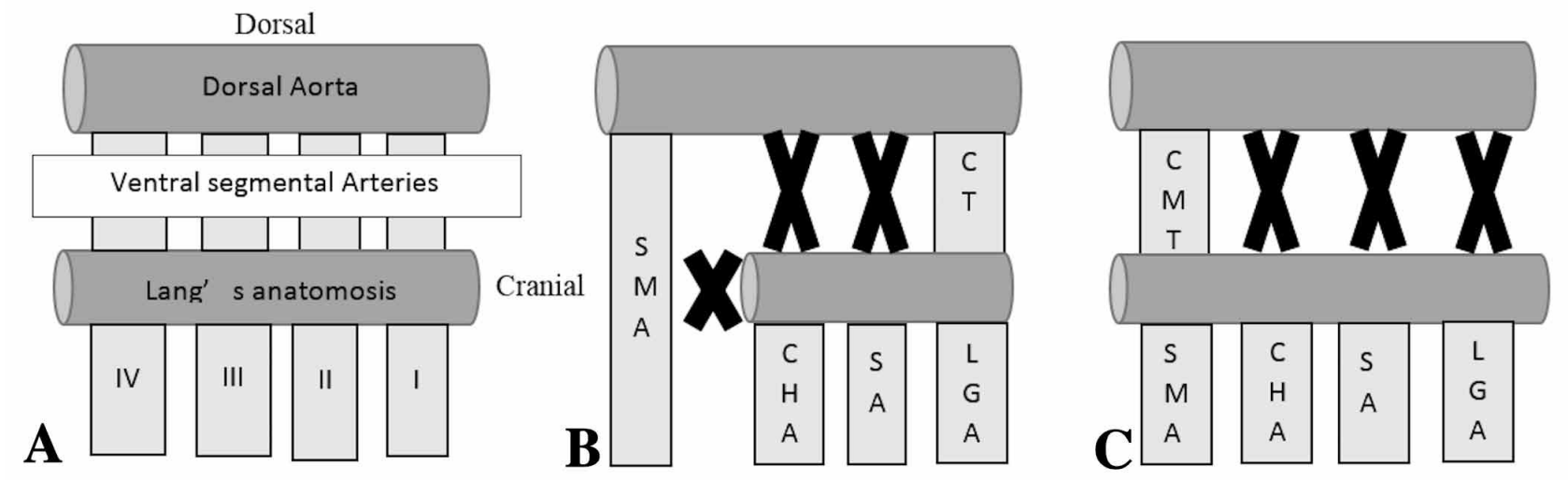

Fig. 2. Illustration showing embryological development of the celiac artery and superior mesenteric artery during weeks 4 to 9 of intrauterine life. A. Illustration of the dorsal aorta, ventral segmental (Vitelline) roots and ventral longitudinal anastomosis (Lang's anastomosis). B. Normal development in adult splanchnic vessels after regression of the second and third roots, and the longitudinal anastomosis to separate the celiac trunk (CT) and the superior mesenteric artery (SMA). The distal part of the first root forms the left gastric artery (LGA), the distal part of the second root forms the splenic artery (SA), and the distal part of the third root forms the common hepatic artery (CHA). C. The celio-mesenteric variant with development of a celio-mesenteric trunk (CMT) follows the ventral anastomosis' failure to dissolve. 


\begin{tabular}{cl}
\multicolumn{2}{c}{ Table I : Michaels' classification of trunk variations } \\
\hline Type & CT branching pattern \\
\hline 1 & Normal branching - trifurcation \\
2 & Hepato splenic trunk \\
3 & Hepatosplenomesenteric trunk \\
4 & Hepatogastrique trunk \\
5 & Splenogastrique trunk \\
6 & Celicomesenteric trunk
\end{tabular}

LAQUIEVRE, A.; HITIER, M.; PETIT, T.; RAVASSE, P.; ROD, J. Tronco Celíaco-Mesentérico Asociado con onfalocele gigante: consecuencias quirúrgicas. Int. J. Morphol., 35(3):938-941, 2017.

RESUMEN: Presentamos el primer caso de un recién nacido que presenta una variación del tronco celíaco-mesentérico asociada con un onfalocele gigante. El tronco celíaco-mesentérico fue inesperado y no se vio durante las etapas del cierre quirúrgico. Después de la reintegración parcial del hígado, el recién nacido presentó hipovolemia refractaria con anuria, lo que condujo a la repetición de la cirugía. Este procedimiento reveló isquemia del hígado y necrosis de todo el tracto gastrointestinal excepto el colon. A pesar del tratamiento, incluyendo la externalización hepática, el bebé no sobrevivió. La autopsia reveló un tronco celíacomesentérico, una rara anomalía caracterizada por un origen común del tronco celíaco y la arteria mesentérica superior, a partir de la aorta. Esta asociación puede explicar las dramáticas consecuencias del procedimiento durante las etapas del cierre. El conocimiento de la asociación de tronco celíaco-mesentérico y onfalocele permitiría al cirujano tomar especial cuidado durante esta delicada cirugía.

PALABRAS CLAVE: Tronco celíaco-mesentérico; Variación arterial mesentérica; Isquemia mesentérica; Onfalocele gigante; Valproato sódico.

\section{REFERENCES}

Ailawadi, G.; Cowles, R. A.; Stanley, J. C.; Eliason, J. L.; Williams, D. M.; Colletti, L. M.; Henke, P. K. \& Upchurch, G. R. Jr. Common celiacomesenteric trunk: aneurysmal and occlusive disease. J. Vasc. Surg., 40(5):1040-3, 2004.

Bauman, B.; Stephens, D.; Gershone, H.; Bongiorno, C.; Osterholm, E.; Acton, R.; Hess, D.; Saltzman, D. \& SegUra, B. Management of giant omphaloceles: Management of giant omphaloceles: A systematic review of methods of staged surgical vs. nonoperative delayed closure. $J$. Pediatr. Surg., 51(10):1725-30, 2016.

Boussemart, T.; Bonneau, D.; Levard, G.; Berthier, M. \& Oriot, D. Omphalocele in a newborn baby exposed to sodium valproate in utero. Eur. J. Pediatr, 154(3):220-1, 1995.

Lee, V.; Alvarez, M. D.; Bhatt, S. \& Dogra, V. S. Median arcuate ligament compression of the celiomesenteric trunk. J. Clin. Imaging Sci., 1:8, 2011.

Lovisetto, F.; Finocchiaro De Lorenzi, G.; Stancampiano, P.; Corradini, C.; De Cesare, F.; Geraci, O,; Manzi, M. \& Arceci, F. Thrombosis of celiacomesenteric trunk: report of a case. World J. Gastroenterol., 18(29):3917-20, 2012.
Michels, N. A. Blood supply and anatomy of the upper abdominal organs, with a descriptive atlas. Philadelphia, Lippincott, 1955.

Michels, N. A.; Siddharth, P.; Kornblith, P. L. \& Parke, W. W. Routes of collateral circulation of the gastrointestinal tract as ascertained in a dissection of 500 bodies. Int. Surg., 49(1):8-28, 1968.

Mitanchez, D.; Walter-Nicolet, E.; Humblot, A.; Rousseau, V.; Revillon, Y. $\&$ Hubert, P. Neonatal care in patients with giant ompholocele: arduous management but favorable outcomes. J. Pediatr. Surg., 45(8):1727-33, 2010

Morita, M. Reports and conception of three anomalous cases of the superior mesenteric arteries. Igaku Kenkyu, 9:1993-2006, 1935.

Tandler, J. Über die Varietäten der Arteria coeliaca und deren Entwicklung. Anat. Hefte., 25:473-500, 1904.

\author{
Corresponding Author: \\ Laquievre Antoine \\ Caen University Hospital \\ Department of Pediatric Surgery \\ Caen, 14033 \\ FRANCE
}

Phone number: +33 (0)2.31.06.44.86

E-mail: antoine.laquievre@gmail.com

Received: 09-03-2017

Accepted: 02-05-2017 